\title{
Pathological Aggression in "Fierce" Mice Corrected by Human Nuclear Receptor 2E1
}

\author{
Brett S. Abrahams, ${ }^{1,2,3}$ Melvin C. H. Kwok, ${ }^{2,3}$ Eric Trinh,, ${ }^{2,3}$ Saeed Budaghzadeh, ${ }^{2,3}$ Sazzad M. Hossain, ${ }^{2,3}$ and \\ Elizabeth M. Simpson ${ }^{1,2,3}$ \\ ${ }^{1}$ Graduate Program in Neuroscience and ${ }^{2}$ Centre for Molecular Medicine and Therapeutics, British Columbia Research Institute for Children's and \\ Women's Health, and ${ }^{3}$ Department of Medical Genetics, University of British Columbia, Vancouver, British Columbia, Canada V5Z 4H4
}

\begin{abstract}
"Fierce" mice, homozygous for the deletion of nuclear receptor 2E1 (NR2E1), show abnormal brain- eye development and pathological aggression. To evaluate functional equivalency between mouse and human NR2E1, we generated mice transgenic for a genomic clone spanning the human NR2E1 locus and bred these animals to fierce mice deleted for the corresponding mouse gene. In fierce mutants carrying human NR2E1, structural brain defects were eliminated and eye abnormalities ameliorated. Excitingly, behavior in these "rescue" mice was indistinguishable from controls. Because no artificial promoter was used to drive transgene expression, promoter and regulatory elements within the human NR2E1 clone are functional in mouse. Normal behavior in rescue animals suggests that mechanisms underlying the behavioral abnormalities in fierce mice may also be conserved in humans. Our data support the hypothesis that variation at NR2E1 may contribute to human behavioral disorders. Use of this rescue paradigm with other genes will permit the direct evaluation of human genes hypothesized to play a causal role in psychiatric disease but for which evidence is lacking or equivocal.
\end{abstract}

Key words: 6q21-6q22; behavior; genetic disease; Tlx; transgenic rescue; violence

\section{Introduction}

The study of mental illnesses is exceedingly difficult. Despite strong evidence for genetic modulation of disease risk (Tandon and McGuffin, 2002), positional cloning has shown only limited success in the identification of psychiatric disease genes. Genetic studies in humans are hampered by the incomplete penetrance of disease features and extensive phenotypic variability among affect individuals, resulting in part from polygenic inheritance (Owen et al., 2004) and gene-environment interactions (Caspi et al., 2002). Moreover, genetic heterogeneity between individuals undermines both population-based strategies and the replication of results by independent groups. Mouse genetics can address these concerns, ensuring near-identical environments and genetic make-up between subjects. Determining the subset of observations from mice that generalize to humans, however, remains challenging because of differences between the species. From this perspective, we reasoned that establishing a paradigm in which one could functionally evaluate the ability of a human

\footnotetext{
Received Nov. 4, 2004; revised May 20, 2005; accepted May 22, 2005.

B.S.A. was supported by Doctoral Research Awards from both the Canadian Institutes of Health Research and the Scottish Rite Charitable Foundation of Canada. S.M.H. was supported by a Jack and Doris Brown Foundation Award. E.M.S. holds a Canada Research Chair in Genetics and Behavior and was supported by the Canada Foundation for Innovation New Opportunities Fund/British Columbia Knowledge Development Fund, the Canadian Institutes of Health Research, and the National Institute of Health Mental Health. We are grateful to Dr. Bruce P. Connop, Dr. Wim E. Crusio, Dr. Liisa A. Galea, Dr. Candace E. Hofmann, Ravinesh A. Kumar, Simon Warby, Bibiana K. Y. Wong, and Dr. Yuanyun Xie for helpful discussion, to Slavita Bohace for technical assistance to Brent Gowen for histological work, to Boris Kuzeljevic and Tracey D. Weir for assistance with statistical analyses, to Wendy Wen for initial help with funduscopy, and to Veronica Yakoleff for aid in manuscript preparation.

Correspondence should be addressed to Elizabeth M. Simpson at the above address. E-mail: simpson@cmmt.ubc.ca.

DOI:10.1523/JNEUROSCI.4757-04.2005

Copyright $\odot 2005$ Society for Neuroscience $\quad 0270-6474 / 05 / 256263-08 \$ 15.00 / 0$
}

gene to shape behavior and simultaneously retain the advantages associated with a model system would be powerful. Toward this end, we generated transgenic mice expressing the human form $[\mathrm{Tg}(\mathrm{Hum})]$ of orphan nuclear receptor 2E1 (NR2E1; previously $M t l l$, Tailless, $T l l$, and $T l x$ ) and evaluated the ability of this human gene to modulate the behavior of mutant mice, which in its absence would have demonstrated pathological violence.

Nr2e1 null mice show hypoplasia of the cortex, olfactory bulb, and retina. Structural abnormalities in mutants are caused by abnormal neuronal proliferation during development as opposed to increased cell death (Stenman et al., 2003b; Miyawaki et al., 2004; Roy et al., 2004). Although the aggression observed in "fierce" is complex, the term pathological appropriately captures several important features. For one, the abnormal behavior is directly attributable to the loss of Nr2e1 (Monaghan et al., 1997; Young et al., 2002). Second, the aggression is habitual, starting at $\sim 5$ weeks and persisting through adulthood (Young et al., 2002). Third, the aggression is maladaptive, with the males often killing their intended mate (Young et al., 2002). Mechanisms underlying behavioral abnormalities remain elusive but may involve developmental abnormalities of the amygdala (Stenman et al., 2003a), olfactory bulb (Monaghan et al., 1997; Yu et al., 2000; Young et al., 2002), or loss of Nr2e1 in adulthood. Independent genome scans for bipolar disorder (Dick et al., 2003; Middleton et al., 2004) find significant linkage with the specific interval to which NR2E1 maps (human 6q21-22).

Our results show that the presence of a transgene spanning human NR2E1 is sufficient to eliminate structural brain defects, ameliorate eye abnormalities, and restore normal behavior to fierce mice. Because no artificial promoter was used to drive transgene expression, promoter and regulatory elements within 
human NR2E1 are functional in mouse. Along with amelioration of developmental abnormalities, demonstration of human NR2E1 in the brains of transgenic animals supports appropriate transcription by the human transgene. The correction of fierce brain-behavior abnormalities by human NR2E1 supports conserved underlying mechanisms for behavior modulation. Moreover, use of this same approach with other genes may prove useful in the genetic dissection of discrete features or behaviors that contribute to psychiatric disease (endophenotypes) as well as the systematic evaluation of candidate genes for which involvement in disease is controversial.

\section{Materials and Methods}

Transgenesis. Pronuclear injection of a $141 \mathrm{~kb}$ PAC clone spanning human NR2E1 (pacEMS1; clone identification number, dJ429G5; GenBank accession number AL078596.7) was performed as described previously (Abrahams et al., 2003) to produce eight transgenic founders from which five independent strains were established successfully. Two strains were used here [C57BL/6J.Cg-Tg(NR2E1pacEMS1B)10Ems and C57BL/ 6J.Cg- $\operatorname{Tg}(N R 2 E 1$ pacEMS1D) 11Ems] with mice at backcross generation 6 (N6) $(98.4 \%$ C57BL/6J) to N10 (99.9\% C57BL/6J) before use. These strains will be represented by $\mathrm{C} 57 \mathrm{BL} / 6 \mathrm{~J}[+/+, \mathrm{Tg}(\mathrm{Hum}) /+]$, or $\operatorname{Tg}$ (Hum). No differences between the two characterized lines, either before or after having been bred to fierce (see below), were observed for animals of any genotype. Moreover, similar results were obtained when the two strains were analyzed either separately or together. For simplicity, data reported here have been pooled across the two strains.

Breeding. Two strains bearing the fierce mutation were used in the breeding strategy (described below) with the transgenics (described above), C57BL/6J.Cg-Nr2e frc (C57BL/6J; fierce/+, +/+) and 129S1/ SvImJ.Cg-Nr2e1 $1^{\text {frc }}$ (129S1/SvImJ; fierce/+, +/+). Both strains had been backcrossed $>10$ times (to C57BL/6J and 129S1/SvImJ, respectively) and thus were $>99.9 \%$ inbred before use. Because males homozygous for $N r 2 e 1^{f r c}$ (referred to as fierce) kill their intended mates and homozygous fierce females are poor mothers (Young et al., 2002), experimental mice were obtained by a two-generation mating scheme involving the pairing of $\mathrm{Nr}_{2 \mathrm{e}}{ }^{\text {frc }}$ heterozygotes. C57BL/6J (fierce/+, +/+) mice were crossed to $\mathrm{C} 57 \mathrm{BL} / 6 \mathrm{~J}[+/+, \mathrm{Tg}(\mathrm{Hum}) /+]$ mice to obtain $\mathrm{C} 57 \mathrm{BL} / 6 \mathrm{~J}[\mathrm{frc} /+$, $\mathrm{Tg}(\mathrm{Hum}) /+]$ females. These females were then crossed to $129 \mathrm{~S} 1 / \mathrm{SvImJ}$ (fierce/,$++/+$ ) males to produce experimental animals. Thus, experimental mice were first generation C57BL/6J × 129S1/SvImJ (B6129F1) offspring. Production of F1s ensured (1) large litters (Banks et al., 2003), increasing yield per mating and as a consequence improving ability to control for gene-environment effects, (2) hybrid vigor, although hydrocephalus is frequent among B6 fierce homozygotes, for example, the same is not true of F1s (Young et al., 2002), and (3) genetically matched experimental animals, inheriting one B6 and one 129 chromosome, thereby differing only at the loci under investigation (Silva et al., 1997). Adult mice (12-24 weeks of age) were used for all analyses.

Genotyping. Three separate PCR assays were used to genotype each individual. oEMS650 (5'-GGCGGAGGGAGCTTAAATAG-3') and oEMS1368 (5'-GATTCATCCTATTCCACAAAGTCA-3') span the fierce deletion region and give a product only in its absence. oEMS1859 (5'-CTGGGCCCTGCAGATACTC- $\left.3^{\prime}\right)$ and oEMS1860 (5'-GGTGGCATGATGGGTAACTC-3') detect mouse but not human NR2E1. oEMS800 (5'-CCCAGCAGCTGCGGTTTTGC-3') and oEMS801 (5'-GCAGCGCTCCAGGCAGGAC-3') detect human but not mouse NR2E1. Reactions were put through 30 cycles of the PCR as described previously (Banks et al., 2003) but with the addition of $10 \%$ DMSO for oEMS1859/60 and 800/801.

Histology. Entire brains were dissected after intracardial perfusion of Avertin-anesthetized mice with formalin. Sectioned brains were prepared from a separate set of animals, killed by cervical dislocation. Brains were rapidly removed, embedded in OCT (VWR Scientific, Delta, British Columbia, Canada), and frozen on dry ice. Cryosections were prepared at $15 \mu \mathrm{m}$, then stained with cresyl violet and luxol fast blue.

Funduscopy. Direct funduscopy was performed between 18 and 24 weeks with a Kowa Genesis small animal fundus camera (Pacific Medical,
Delta, British Columbia, Canada) in conjunction with a Volk 90D lens (Topcon Canada, Calgary, Alberta, Canada) as described previously (Hawes et al., 1999). Eyes were dilated with $25 \%$ atropine $30 \mathrm{~min}$ before examination, at which time mice were lightly sedated with Avertin.

Behavior testing. Mice were housed under a reverse light/dark cycle and tested in the dark (Hossain et al., 2004). Because of the aggressive nature of the fierce animals, approved procedures require they be housed singly. Thus, to control for the possible confound of environmental effects (Van Loo et al., 2001) and gene-environment interactions (Ouagazzal et al., 2003) on behavior, all experimental mice [wild type (Wt), fierce, $\mathrm{Tg}$ (Hum), and rescue] were housed individually from weaning at $18 \mathrm{~d}$ until they were killed for histological analyses in adulthood.

Struggle was measured in males and females at 13 weeks for 3 min using a PHM-300TSS mouse tail suspension system (Med Associates, St. Albans, VT). The apparatus was calibrated to offset animal weight before testing, and system settings for struggle and gain were 15 and 4, respectively. Percentage of time struggling was calculated by expressing the number of milliseconds during which force exceeded the struggle threshold (set to 15) as a proportion of test time. Force-exerted struggling was calculated by summing the force applied to the system across the testing period. Significant correlations (ranging from 0.96 to 0.97 ) between experienced human raters and the device we used have been reported recently (Crowley et al., 2004).

Spontaneous activity was measured in mice of both sexes at 12 weeks using a 3 min open-field paradigm. The apparatus we used (Med Associates) was Digiscan photocell-equipped to permit automated data capture. Ambulatory counts equaled the number of beam breaks recorded during the test period. Ambulatory time represented the amount of time (in seconds) spent in motion during the test period. Number of ambulatory episodes was calculated by summing the number of individual episodes (defined as a series of sequential ambulatory counts separated in time by no more than $500 \mathrm{~ms}$ ).

A 4-10 min resident-intruder paradigm (Young et al., 2002) was used to assess aggression in 16- to 18-week-old experimental males. Wild-type mice matched to experimental animals for genetic background, sex, and weight served as intruders. Video analysis software (Observer Video Pro; Noldus Information Technology, Leesburg, VA) was used to score frequency and duration of tail rattling (rapid quivering or thrashing of the tail), wrestling (close contact that escalates to rolls and tumbling), attack (biting of the opponent mouse), sniffing (sniffing the head or snout of the partner), and anogenital investigation (exploration of the intruder's hindquarters). Tail rattling, wrestling, and attack behaviors were combined to give an index of aggression. Aggression per minute and percentage of time aggressive were calculated by expressing the number of aggressive behaviors and time engaged in aggressive behaviors over minutes of testing and as a proportion of total test time, respectively. Sniffing and anogenital investigation were combined to give an index of social behavior. Percentage of time social was calculated by expressing the amount of time engaged in social behaviors as a proportion of total test time.

Statistical analyses. All analyses were performed using JMP 4.0 (SAS Institute, Cary, NC). Continuous data were analyzed by group for normality and equal variances, then compared by parametric (ANOVA for genotype followed by Tukey-Kramer test for pair-wise comparisons when $p<0.05$ ) or nonparametric statistics (Wilcoxon/Kruskal-Wallis test) as necessary. Significant Wilcoxon/Kruskal-Wallis results $(p<$ $0.05)$ were attributed to a single group when results became nonsignificant $(p>0.05)$, after the removal of that group from the original data set. Nominal data (radial asymmetry and mottling) were analyzed using the Pearson $\chi^{2}$ test, with $p<0.05$ taken as the cutoff for significance.

Reverse transcriptase-PCR. Total RNA was isolated from adult mouse brain using TriZol (Invitrogen, Burlington, Ontario, Canada) or in the case of fetal human brain, purchased from Origene (Rockville, MD). Five micrograms of DNaseI-treated RNA were subsequently concentrated using MicronYM-100 columns (Millipore, Nepean, Ontario, Canada) and used to generate oligo-dT primed cDNA with Superscript II according to the manufacturer's instructions (Invitrogen). A reverse transcriptasenegative $(\mathrm{RT}-)$ control was generated in parallel to each cDNA produced. Intron-spanning PCR assays specific for NR2E1 in human or 
mouse were developed. oEMS1633 (5'-GCATGAATACTGACAACACAGAC-3') and oEMS1637 (5'-GCTAATTGACCGTAAAGCTGGT$3^{\prime}$ ) gave a 324 bp product only when mouse $\mathrm{Nr} 2 \mathrm{e} 1$ was present. oEMS749 (5' -TTCCTGAAGGCTACACATTCC-3') and oEMS825 (5'-AGAGGTGGTGGCTCGATTTA- $3^{\prime}$ ) gave a 475 bp product positive only in the presence of human NR2E1. Each primer set was carried through two rounds of PCR, whereby $2 \mu \mathrm{l}$ from a 25 -cycle first reaction was used as template for a 30 -cycle second reaction. An additional primer set against human $\beta$-actin was used to confirm the presence and absence of cDNA in all RT + and RT - samples, respectively, across 30 cycles of PCR. oEMS1646 (5'-ATTGGCAATGAGCGGTTCCGC-3') and oEMS1647 (5'-CTCCTGCTTGCTGATCCACATC-3') give a 336 bp product against either mouse or human cDNA. Parameters for denaturation $\left(94^{\circ} \mathrm{C}\right.$ for $\left.30 \mathrm{~s}\right)$, annealing $\left(55^{\circ} \mathrm{C}\right.$ for $\left.60 \mathrm{~s}\right)$, and extension $\left(72^{\circ} \mathrm{C}\right.$ for $\left.60 \mathrm{~s}\right)$ were kept constant across all assays. Each assay was repeated in a minimum of four animals from each genotype.

\section{Results}

To test the functionality of human NR2E1 in mice, we established transgenic mice harboring a genomic DNA clone spanning the human NR2E1 locus. We then crossed transcription-positive strains (data not shown) to fierce mice shown previously to carry a deletion that spans $N r 2 e 1$ but leaves neighboring genes intact and transcriptionally active (Kumar et al., 2004). Previously identified abnormalities that make up core features of $\mathrm{Nr} 2 \mathrm{e} 1$ mutants were then used to make blinded comparisons between mice from each of the following four groups: wild-type $(+/+,+/+)$, fierce (fierce/fierce, $+/+$ ), transgenic $[+/+, \operatorname{Tg}(\operatorname{Hum}) /+]$, and rescue [fierce/fierce, $\operatorname{Tg}(\mathrm{Hum}) /+$ ].

\section{Human NR2E1 corrects structural brain abnormalities seen in the fierce mouse}

Multiple brain abnormalities in fierce but not transgenic or rescue mice (Fig. 1) were present at the gross and microscopic level. Compared with wild-type controls, fierce brains showed gross hypoplasia of the olfactory bulbs (Fig. 1a, arrow) and anterior cortex, leaving midbrain colliculi exposed (Fig. 1 $a$, between dashed lines). Quantitative analysis of surface areas for the olfactory bulbs (Fig. 1b) and cortex (Fig. 1c) confirmed significant reductions in both regions ( 49.1 and $38.9 \%$, respectively) for fierce relative to each of the other genotypes. In contrast, brains of wild-type, transgenic, and rescue mice were phenotypically indistinguishable.

\section{Human NR2E1 corrects abnormalities observed in sections from fierce forebrain}

We observed characteristic abnormalities in sectioned brains from every fierce mouse examined but no abnormalities in any transgenic or rescue animals (Fig. 2). Sections through the fierce forebrain showed an overall reduction in size relative to wild-type controls (Fig. 2a). An unusually shaped cingulum, poorly defined piriform cortex, and smaller anterior commissure were also evident in fierce. At higher magnification, abnormal cortical lamination was noted (Fig. $2 b$ ), consistent with the previous observation (Land and Monaghan, 2003) that Nr2e1 is required for proper formation of layers II and III. A reduction in striatal volume was also observed in fierce (Fig. $2 c$ ) as a result of misspecification of the ventral lateral ganglionic eminence from which it develops (Stenman et al., 2003b). Fierce mice showed an enlargement of corticostriatal fibers that pass through the striatum (Fig. $2 c$, arrows), with clustering toward its medial border. In addition, the external capsule of the corpus callosum was thin in fierce relative to wild type (Fig. $2 c$ ).
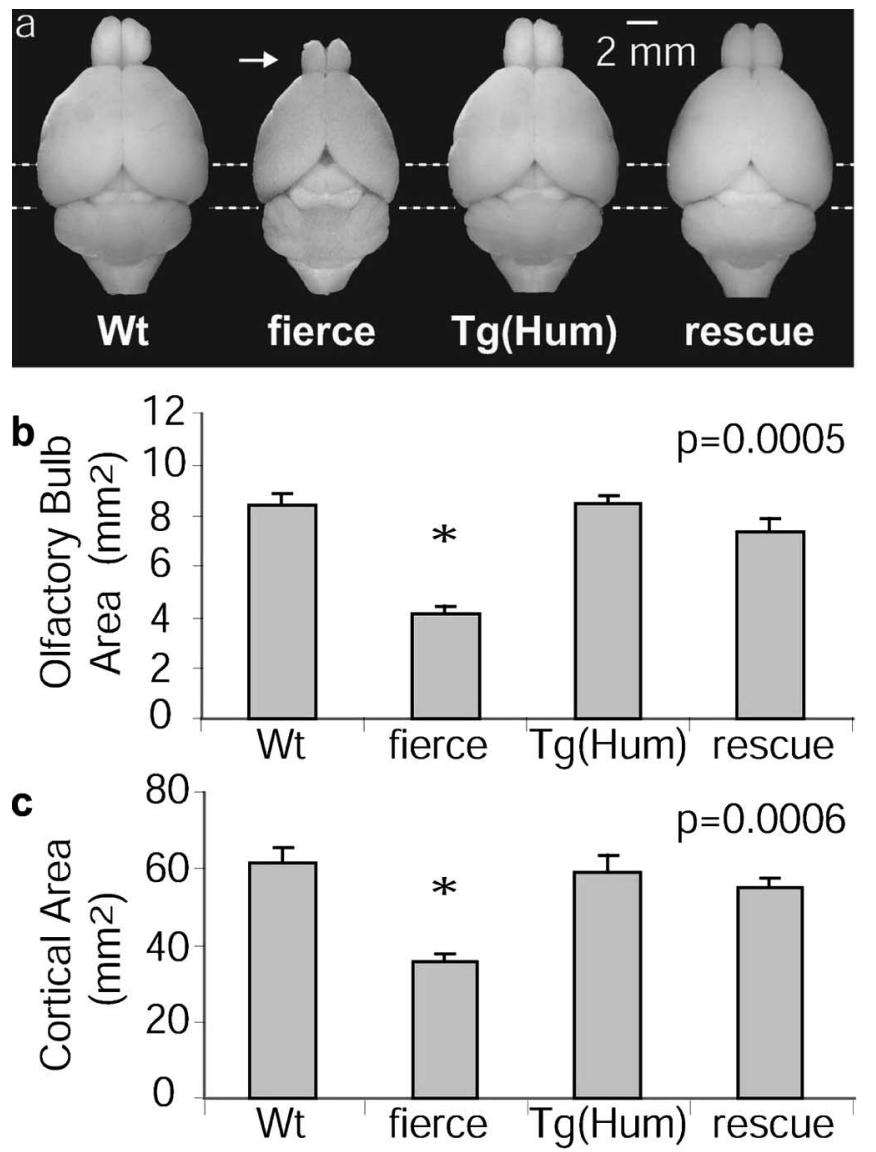

Figure 1. Human NR2E1 corrects structural abnormalities seen in the fierce olfactory bulbs and forebrain. $\boldsymbol{a}$, Reduced olfactory bulb size (arrow) and incomplete extension of the cortex (dashed lines) were observed only in fierce. In contrast, Wt, transgenic, and rescue brains were indistinguishable. The surface areas (in square millimeters) of the olfactory bulbs $(\boldsymbol{b})\left[H_{(3,34)}=\right.$ $17.5854 ;{ }^{*} p=0.0005 ; n=11,6,8,9$ for Wt, fierce, $\mathrm{Tg}$ (Hum), and rescue, respectively] and cortex $(c)\left[H_{(3,38)}=17.4616 ;{ }^{*} p=0.0005 ; n=11,8,9,10\right.$ for Wt, fierce, $\mathrm{Tg}$ (Hum), and rescue, respectively] were significantly different between groups as a result of fierce alone. Error bars represent SEM.

Human NR2E1 ameliorates multiple aspects of the fierce eye Abnormalities observed in the fierce eye by funduscopy were each corrected or ameliorated in transgenic and rescue animals (Fig. $3 a$ ). Asymmetry of the radial vasculature, mottling of the retinal pigment epithelium (Fig. $3 a$, arrow), and a reduction in retinal vessel number were characteristic features of the fierce eye. All fierce mice showed abnormal radial symmetry, and thus radial symmetry was significantly reduced relative to wild-type, transgenic, and rescue mice (Fig. $3 b$ ). Similarly, only fierce showed mottling of the retinal pigment epithelium (Fig. 3c). Vessel number was lowest in fierce and significantly reduced relative to rescue mice, which showed the next lowest vessel number (Fig. $3 d$, dagger). However, for vessel number only, rescue animals were reduced significantly relative to wild-type and transgenic mice (Fig. 3d, double dagger). Nevertheless, because rescue eyes were essentially normal both by qualitative and quantitative analyses, we conclude that the presence of human NR2E1 had a corrective influence on the structural development of the fierce eye. The slight reduction in vessel number may reflect the observation by others that development of the mouse eye is exquisitely sensitive to changes in gene dosage (Schedl et al., 1996; Brown et al., 1998; Chang et al., 2001). 

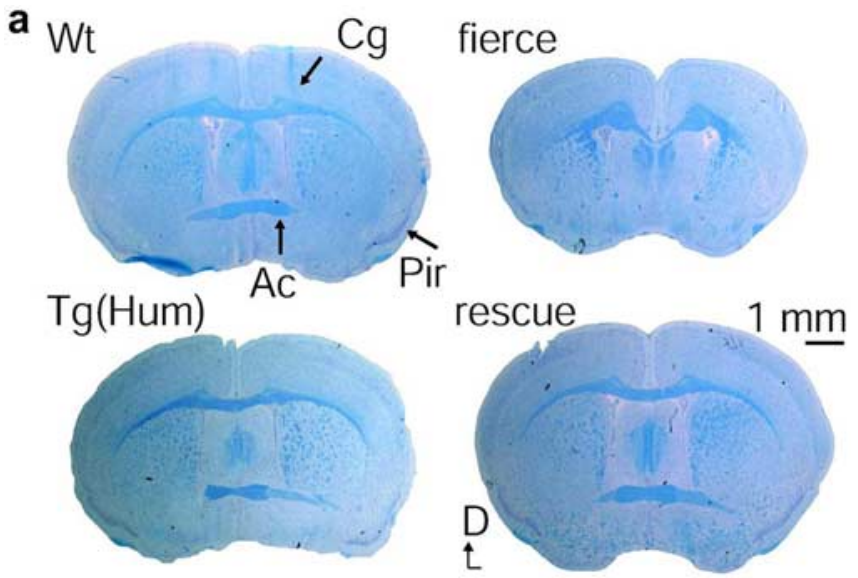

b
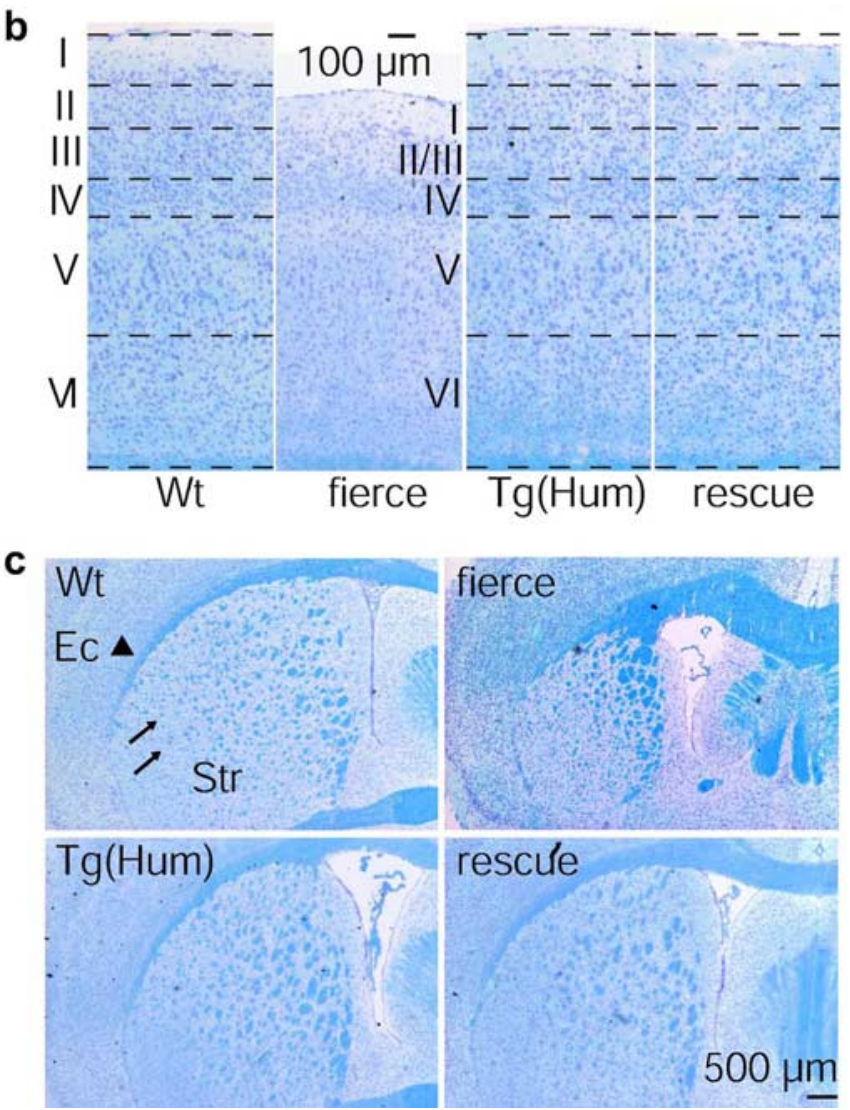

Figure 2. Human NR2E1 corrects abnormalities observed in forebrain sections. $\boldsymbol{a}$, Fierce coronal sections were small and showed abnormalities of the cingulum $(\mathrm{Cg})$, piriform cortex (Pir), and anterior commissure (Ac). D, Dorsal. $\boldsymbol{b}$, The fierce cortex was shortened, consistent with hypoplasia across layers II and III. c, The striatum (Str) was underdeveloped in fierce, whereas corticostriatal fibers (arrows) were enlarged and clustered medially. The arrowhead indicates the $\mathrm{Ec}$, which is thin in fierce to WE. In contrast, transgenic and rescue sections were indistinguishable from Wt. Sections [bregma, $+0.26 \mathrm{~mm}$ (Franklin and Paxinos, 1997)] were stained with cresyl violet and luxol fast blue $[n=4,5,2,5$ for Wt, fierce, $\operatorname{Tg}(\mathrm{Hum})$, and rescue, respectively].

\section{Human NR2E1 corrects behavior abnormalities in the} fierce mouse

Multiple behavior tests identified fierce mice as distinct from the three other groups, whereas no differences were found between wild-type, transgenic, and rescue animals. We used a tailsuspension test to quantify the hard-to-handle phenotype observed previously in fierce mice (Monaghan et al., 1997; Young et al., 2002).

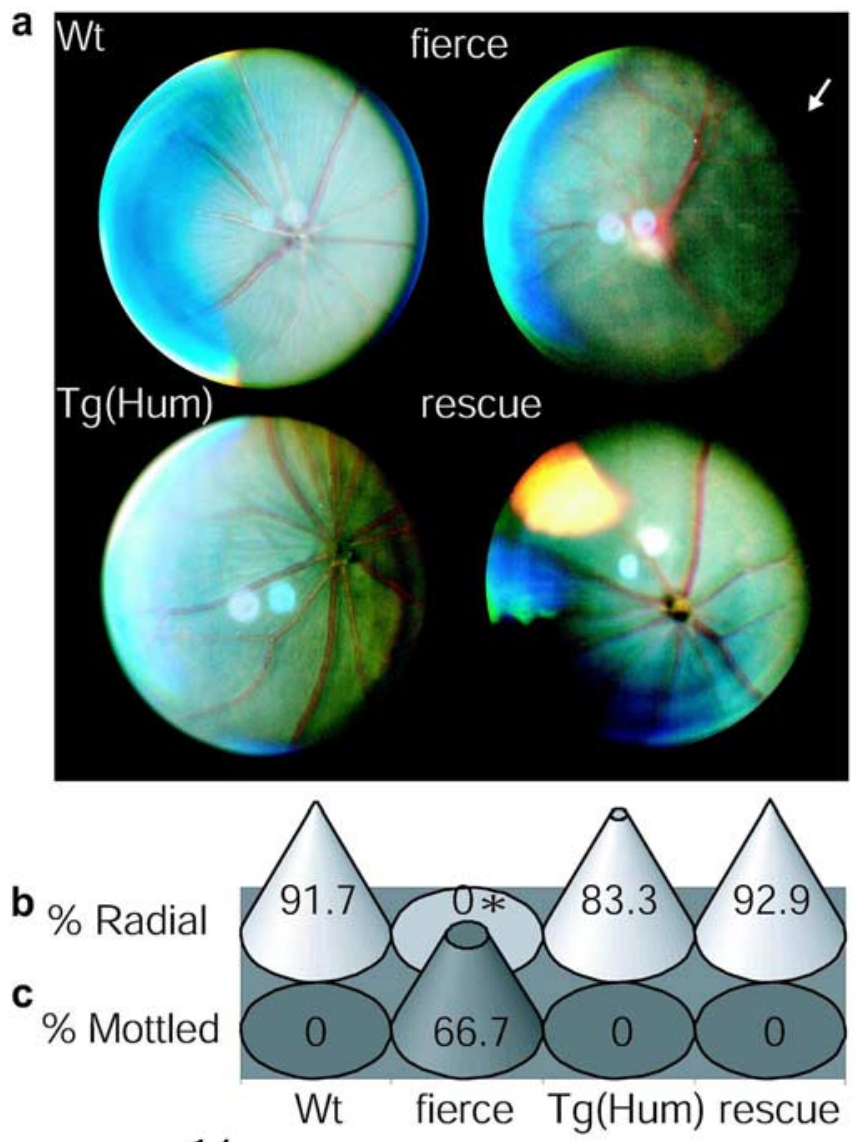

d

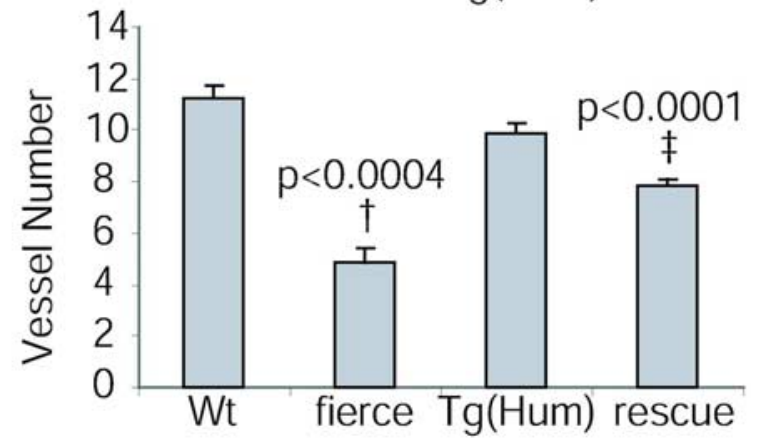

Figure 3. Human NR2E1 ameliorates multiple aspects of the fierce eye. $\boldsymbol{a}$, Fierce fundus photos show radial asymmetry, mottling (arrow), and reduced vessel number. $\boldsymbol{b}$, Asymmetry was unique to fierce $\left[\chi_{(3,46)}^{2}=9.644 ;{ }^{*} p<0.0001 ; n=12,8,12,14\right.$ for Wt, fierce, $\mathrm{Tg}$ (Hum), and rescue, respectively]. $c$, Only fierce showed mottled pigment epithelium $\left[\chi_{(3,32)}^{2}=6.3\right.$; $p=0.0978 ; n=12,6,7,7$ for Wt, fierce, $\operatorname{Tg}($ Hum $)$, and rescue, respectively]. $\boldsymbol{d}$, Fierce vessel number was significantly reduced relative to rescue $\left(H_{(1,21)}=12.3144 ;{ }^{\dagger} p<0.0004 ; n=7,14\right.$ for fierce and rescue, respectively). Rescue vessel number was significantly reduced relative to Wt and $\operatorname{Tg}($ Hum $)\left[H_{(2,34)}=21.4298 ;{ }^{\ddagger} p<0.0001 ; n=11,12,14\right.$ for Wt, $\operatorname{Tg}$ (Hum), and rescue, respectively]. Error bars represent $S E M$.

In fierce mice, percentage of time struggling and force exerted struggling were significantly increased relative to mice of other genotypes (Fig. 4a,b). Similarly, fierce showed significant increases in spontaneous activity relative to the other groups as measured by ambulatory counts (Fig. 4c), ambulatory time (Fig. $4 d$ ), and ambulatory episodes (Fig. 4e). Additional measures obtained during this test also showed significant differences between fierce and all other genotypes (increased ambulatory distance and decreased resting time; data not shown). Fierce mice showed significantly heightened aggression in the resident-intruder test relative to the other genotypes (Fig. $4 f, g$ ). The propor- 
a

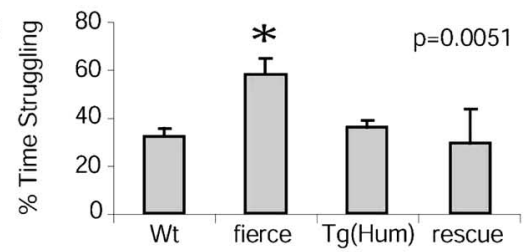

b 600 * $\quad$ p $=0.0048$

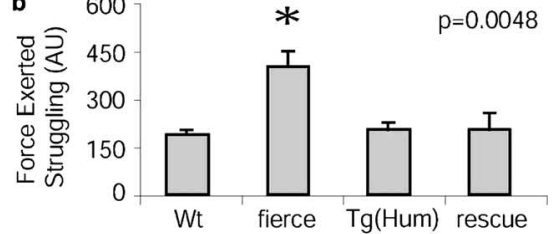

c

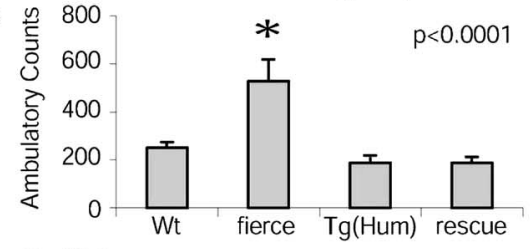

d $\cong$ 50.0

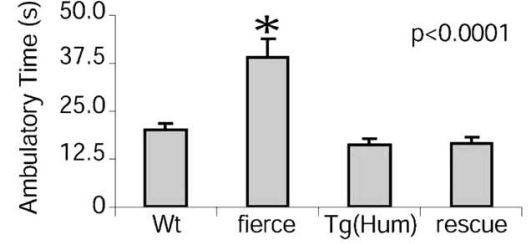

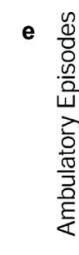
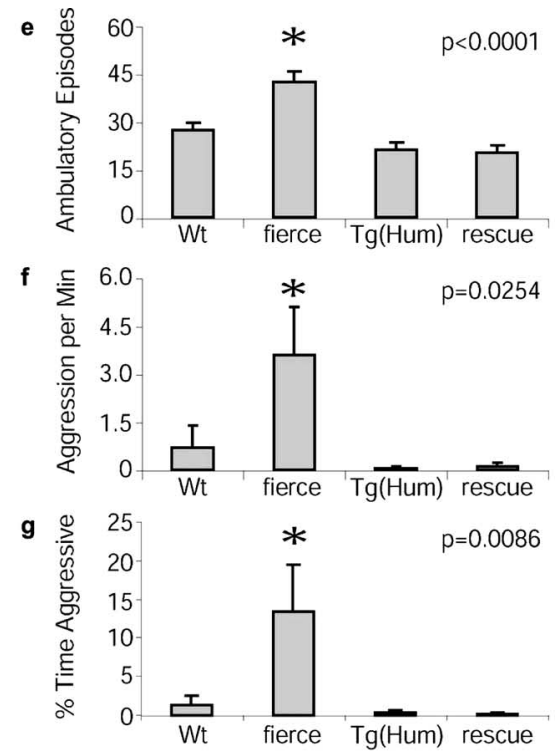

h

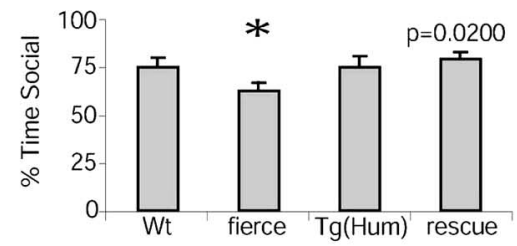

Figure 4. Human NR2E1 corrects fierce behavior. In a tail suspension test, fierce was significantly different from other groups for percentage of time struggling $(\boldsymbol{a})\left[H_{(3,47)}=12.7877 ;{ }^{*} p=0.0051 ; n=16,6,15,10\right.$ for Wt, fierce, $\mathrm{Tg}(\mathrm{Hum})$, rescue $]$ and force exerted struggling $(\boldsymbol{b})\left(H_{(3,47)}=12.9260 ;{ }^{*} p=0.0048\right)$. In an open-field test, number of ambulatory counts $(\boldsymbol{c})\left[H_{(3,57)}=\right.$ 23.2696; ${ }^{*} p<0.0001 ; n=17,12,17,11$ for Wt, fierce, $\operatorname{Tg}($ Hum $)$, and rescue, respectively], total ambulatory time $(\boldsymbol{d})\left(H_{(3,57)}=\right.$ $\left.25.4062 ;{ }^{*} p<0.0001\right)$, and number of ambulatory episodes $(\boldsymbol{e})\left(H_{(3,57)}=14.2440 ;{ }^{*} p<0.0001\right)$ were all significantly elevated in fierce. Aggression in a resident-intruder paradigm was also elevated; instances of aggression per minute $(\boldsymbol{f})\left[H_{(3,49)}=9.3130\right.$; ${ }^{*} p<0.0254 ; n=14,7,12,16$ for Wt, fierce, $\mathrm{Tg}(\mathrm{Hum})$, and rescue, respectively] and the percentage of time engaged in aggressive behaviors $(\boldsymbol{g})\left(H_{(3,49)}=11.6736 ;{ }^{*} p<0.0086\right)$ were increased significantly in fierce relative to other genotypes. In addition, the percentage of time engaged in social behaviors $(\boldsymbol{h})$ was reduced in fierce relative to all other genotypes $\left(H_{(3,49)}=\right.$ 9.8362; $\left.{ }^{*} p<0.0200\right)$. No significant differences were observed between the other three groups in any of the measures assessed in any of the three paradigms. AU, Arbitrary units. Error bars represent SEM.

tion of time fierce mice engaged in social behavior was reduced relative to mice from each of the other genotypes (Fig. 4h). Most strikingly, unlike fierce males who attack, wound, and kill female mates (Young et al., 2002), male rescue animals were not aggressive toward female partners and mated successfully. Together, these results indicate that the presence of human NR2E1 renders the behavior of fierce mice indistinguishable from that of wildtype controls.

\section{Human NR2E1 message is present in the brains of adult transgenic and rescue mice}

$N R 2 E 1$ is normally expressed during embryogenesis and in the adult brain of mice and humans. Thus, although embryonic expression would be essential, the question arose whether rescue of the fierce phenotype had occurred in the absence or presence of adult expression of the human transgene. cDNA prepared from human brain and the brains of adult mice corresponding to each of the genotypes under investigation were assayed for the presence of mouse Nr2e1 (Fig. 5a), human NR2E1 (Fig. 5b), and $\beta$-actin (Fig. $5 c$ ). RT + and RT - aliquots of individual samples were run in adjacent lanes to demonstrate that signal was RT dependant. Human brain (Fig. 5, RT+, lane 2) gave no signal for mouse Nr2e1 (top) but was positive for each of human NR2E1 (middle) and $\beta$-actin (bottom). cDNA from wild-type (Fig. 5,
$\mathrm{RT}+$, lane 4) was positive for mouse $\mathrm{Nr} 2 e 1$ (top), negative for human NR2E1 (middle), and positive for $\beta$-actin (bottom). cDNA corresponding to the fierce mutant (Fig. 5, RT +, lane 6) was negative for each of mouse Nr2e1 (top) and human NR2E1 (middle) but positive for $\beta$-actin (bottom). Transgenic samples (Fig. 5, RT+, lane 8) were positive for each of mouse Nr2e1 (top), human NR2E1 (middle), and $\beta$-actin (bottom). Rescue mice (Fig. 5, $\mathrm{RT}+$, lane 10) were negative for mouse $\mathrm{Nr} 2 \mathrm{e} 1$ (top) but positive for each of human NR2E1 (middle) and $\beta$-actin (bottom). None of the RT - samples (lanes 3, 5, 7, 9, or 11) gave rise to any product for any of the three assays. Thus, there was adult expression of the human transgene in the rescue mice, further strengthening the conclusion of functional homology of the coding and regulatory sequences of human and mouse NR2E1 but not allowing for temporal dissection of NR2E1 function.

\section{Discussion}

We show here that the presence of human NR2E1 was sufficient to eliminate structural brain abnormalities while ameliorating eye abnormalities in fierce mice deleted for mouse Nr2el. We further demonstrate that the presence of human NR2E1 was able to correct the pathological aggression and other behavioral abnormalities normally present in fierce. Our data demonstrating the presence of transgene-derived human NR2E1 in the brains of adult transgenic and rescue mice provides additional support for shared function between the mouse and human gene homologs. Together, these data suggest that NR2E1 protein and regulatory sequences are comparable between mice and humans. Our data also demonstrate that conservation is sufficient to maintain the function of both upstream and downstream signaling pathways, at least in mice. Finally, we describe an experimental system in which to test the functional consequences of specific human NR2E1 alleles on behavior. Such a system may also be useful in understanding the specific role of NR2E1 in risk for psychiatric illness and the manner by which this risk interacts with changes in the environment.

\section{Mechanisms underlying NR2E1 behavior modulation conserved to human}

Transgenic rescue experiments in which a human gene is studied in a mouse background have proven useful previously in the analysis of gene function in vivo (Schedl et al., 1996; Chen et al., 2002; Cheung et al., 2004). Although increasingly common in disciplines outside of psychiatry, only a handful of experiments within the discipline have used the approach. Those that do have shown correction of embryonic lethality by a human gene (Hodgson et al., 1996; Pook et al., 2001) but not abnormal behavior (Peier et al., 2000). Thus, before the studies described here, it was unclear whether a human gene could correct abnormal be- 


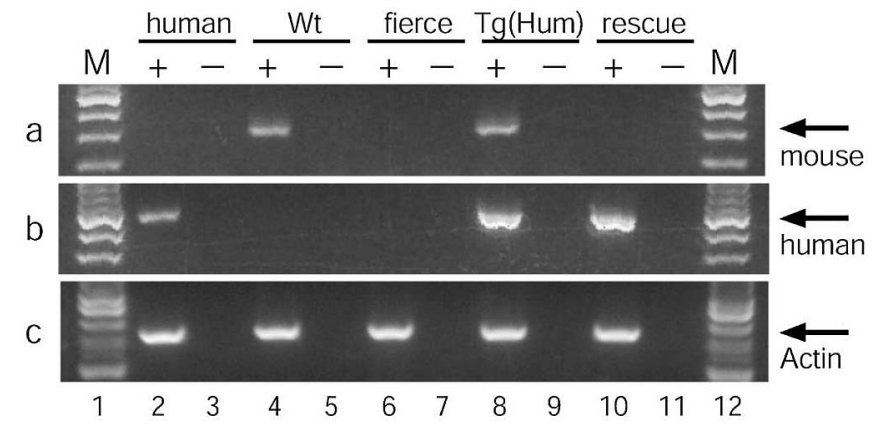

Figure 5. Human NR2E1 message is present in the brains of adult transgenic and rescue mice. $\boldsymbol{a}$, An RT-PCR assay for mouse Nr2el gave amplification products in RT+ samples from brains of wild-type (lane 4) and transgenic (lane 8) but not human (lane 2), fierce (lane 6), or rescue (lane 10) mice. $\boldsymbol{b}$, A second RT-PCR assay specific for human NR2E1 gave amplification products for RT + samples prepared from human (lane 2), transgenic (lane 8 ), and rescue (lane 10) but neither wild type (lane 4) nor fierce (lane 6). c, Amplification products for $\beta$-actin were present in all RT + samples (lanes $2,4,6,8,10$ ), confirming CDNA integrity. No amplification products were seen in any RT - samples (lanes 3, 5, 7,9, 11). A DNA marker (M) was run in lanes 1 and 12.

havior in mutant mice. By extension, the conservation of genetic mechanisms underlying the modulation of behavior was similarly unknown.

\section{From mouse behavior to human disease}

The function of NR2E1 itself is also complex and the subject of active investigation (Stenman et al., 2003a,b; Miyawaki et al., 2004; Roy et al., 2004; Shi et al., 2004). However, an emerging hypothesis suggests that the primary function of this nuclear receptor is to suppress the differentiation of neuronal stem cells (Younossi-Hartenstein et al., 1997; Nguyen et al., 1999; Shi et al., 2004). Consistent with this hypothesis, Nr2el is transcribed in the embryonic and adult mouse within regions important for neurogenesis (Monaghan et al., 1995; Shi et al., 2004). Moreover, although mice deleted for $\mathrm{Nr} 2 \mathrm{e} 1$ show a complex series of phenotypic abnormalities (Monaghan et al., 1997; Yu et al., 2000; Young et al., 2002), the developmental hypoplasia observed within the forebrain, eye, and olfactory bulbs may be secondary to a reduced proliferative capacity. Thus, at the cellular level, NR2E1 may normally act to suppress differentiation, thereby enabling an expansion of the neuronal stem cell pool ultimately available for neurogenesis. Our data support this hypothesis but do not speak to whether the abnormal behavior observed in fierce mice is the result of abnormal development or the absence of NR2E1 signaling in adulthood. Because the human transgene, like mouse $N r 2 e 1$, appears to be expressed during development and adulthood, it is not possible, with the strains we have established, to examine the extent to which signaling at each stage may be required for normal behavior. Conditional ablation of the endogenous gene in adulthood or conditional rescue of expression through development alone would be informative in this regard. Furthermore, although our data also support the conservation of mechanisms underlying behavior abnormalities between mouse and human, the clinical presentation of a common cellular defect may be phenotypically distinct between species. Thus, the data we present here do not demonstrate that a human homozygous for a deletion at NR2E1 would be phenotypically similar to the fierce mouse, although they are consistent with this hypothesis. Although speculative, it is also possible that more subtle variation in human NR2E1 may predispose toward abnormal behavioral phenotypes. This hypothesis is bolstered by evi- dence for linkage with bipolar disorder at human 6q21-22 (Dick et al., 2003; Middleton et al., 2004); however, NR2E1 is only one among many good candidates within this interval. Of additional interest is that NR2E1-interacting genes (Kobayashi et al., 2000; Yu et al., 2000; Stenman et al., 2003a; Shi et al., 2004) are themselves implicated in mental illness (Goodman, 1998; Krezel et al., 1998; Heyman et al., 1999; Stober et al., 1999; Buervenich et al., 2000; Chen et al., 2001; Davis et al., 2002; Iwayama-Shigeno et al., 2003; Rothermundt et al., 2004). If and when association studies implicate specific human NR2E1 alleles in psychiatric disease, the functional evaluation of these candidates in our system would be of particular interest.

\section{Rescue of fierce mouse behavior unexpected}

We were surprised at obtaining complete correction of brain and behavior abnormalities in the fierce mouse despite only four amino acid differences between the mouse and human NR2E1 proteins. First, it is well established that subtle structural differences within gene orthologs from closely related species can give rise to striking phenotypic variation (Enard et al., 2002). Second, $\mathrm{Nr} 2 e 1$ transcript distribution in mouse is both spatially complex and temporally dynamic. It is first seen at approximately embryonic day 8 (E8) in a few adjacent neuroepithelial cells at the anterior limit of the prosensencephalon, but by E8.5, the transcript has spread to the presumptive diencephalon and is also present in the newly formed optic and olfactory evaginations (Monaghan et al., 1995). Transcription peaks at E13.5 in ventricular and subventricular zones and although almost undetectable in the perinatal brain (Monaghan et al., 1995), is seen later in the adult brain at high levels in the dentate gyri and subventricular zones and at lower levels scattered throughout the cortex (Shi et al., 2004). Because data from human are limited (Jackson et al., 1998), it was unclear whether the expression of the molecule is entirely conserved either in place or across development. Third, NR2E1 acts in more than one cell type (Shi et al., 2004), and at least one of its functions appears to be cell-type specific (Kobayashi et al., 2000). Given the ability of the human transgene to ameliorate developmental anomalies in brain and eye structure, however, we would suggest that the embryonic distribution of transgene-derived human NR2E1 must at least approximate that of the wild-type allele. Moreover, the presence of human NR2E1 in the brains of adult transgenic and rescue mice provides additional support for functional equivalency between the mouse and human gene homologs.

\section{Human rescue paradigm: a useful tool for psychiatric research}

Our data represent the first example of a human gene correcting mouse behavior. Whereas cell-based endpoints are suitable for some kinds of disease, others, particularly psychiatric disorders, require in vivo assay systems. Moreover, as the number of coding variants, and most importantly, noncoding variants implicated in disease increases, so will the need for systems in which to assess their function. We have established an experimental paradigm in which to functionally evaluate the role of human NR2E1 alleles in the modulation of whole-animal behavior. Experiments similar to those we have described will be useful to clarify the role of other genes and alleles in human behavior and psychiatric disease.

\section{References}

Abrahams BS, Chong ACO, Nisha M, Milette D, Brewster DA, Berry ML, Muratkhodjaev F, Mai S, Rajcan-Separovic E, Simpson EM (2003) 
Metaphase FISHing of transgenic mice recommended: FISH and SKY define BAC-mediated balanced translocation. Genesis 36:134-141.

Banks KG, Johnson KA, Lerner CP, Mahaffey CL, Bronson RT, Simpson EM (2003) Retroposon compensatory mechanism hypothesis not supported: Zfa knockout mice are fertile. Genomics 82:254-260.

Brown NL, Kanekar S, Vetter ML, Tucker PK, Gemza DL, Glaser T (1998) Math5 encodes a murine basic helix-loop-helix transcription factor expressed during early stages of retinal neurogenesis. Development 125:4821-4833.

Buervenich S, Carmine A, Arvidsson M, Xiang F, Zhang Z, Sydow O, Jonsson EG, Sedvall GC, Leonard S, Ross RG, Freedman R, Chowdari KV, Nimgaonkar VL, Perlmann T, Anvret M, Olson L (2000) NURR1 mutations in cases of schizophrenia and manic-depressive disorder. Am J Med Genet 96:808-813.

Caspi A, McClay J, Moffitt TE, Mill J, Martin J, Craig IW, Taylor A, Poulton R (2002) Role of genotype in the cycle of violence in maltreated children. Science 297:851-854.

Chang B, Smith RS, Peters M, Savinova OV, Hawes NL, Zabaleta A, Nusinowitz S, Martin JE, Davisson ML, Cepko CL, Hogan BL, John SW (2001) Haploinsufficient Bmp4 ocular phenotypes include anterior segment dysgenesis with elevated intraocular pressure. BMC Genet 2:18.

Chen JY, Levy-Wilson B, Goodart S, Cooper AD (2002) Mice expressing the human CYP7A1 gene in the mouse CYP7A1 knock-out background lack induction of CYP7A1 expression by cholesterol feeding and have increased hypercholesterolemia when fed a high fat diet. J Biol Chem 277:42588-42595.

Chen YH, Tsai MT, Shaw CK, Chen CH (2001) Mutation analysis of the human NR4A2 gene, an essential gene for midbrain dopaminergic neurogenesis, in schizophrenic patients. Am J Med Genet 105:753-757.

Cheung C, Akiyama TE, Ward JM, Nicol CJ, Feigenbaum L, Vinson C, Gonzalez FJ (2004) Diminished hepatocellular proliferation in mice humanized for the nuclear receptor peroxisome proliferator-activated receptor alpha. Cancer Res 64:3849-3854.

Crowley JJ, Jones MD, O'Leary OF, Lucki I (2004) Automated tests for measuring the effects of antidepressants in mice. Pharmacol Biochem Behav 78:269-274.

Davis S, Thomas A, Perry R, Oakley A, Kalaria RN, O’Brien JT (2002) Glial fibrillary acidic protein in late life major depressive disorder: an immunocytochemical study. J Neurol Neurosurg Psychiatry 73:556-560.

Dick DM, Foroud T, Flury L, Bowman ES, Miller MJ, Rau NL, Moe PR, Samavedy N, El-Mallakh R, Manji H, Glitz DA, Meyer ET, Smiley C, Hahn R, Widmark C, McKinney R, Sutton L, Ballas C, Grice D, Berrettini W, et al. (2003) Genomewide linkage analyses of bipolar disorder: a new sample of 250 pedigrees from the National Institute of Mental Health Genetics Initiative. Am J Hum Genet 73:107-114.

Enard W, Przeworski M, Fisher SE, Lai CS, Wiebe V, Kitano T, Monaco AP, Paabo S (2002) Molecular evolution of FOXP2, a gene involved in speech and language. Nature 418:869-872.

Franklin KBJ, Paxinos G (1997) The mouse brain in stereotaxic coordinates, Ed 1. London: Academic.

Goodman AB (1998) Three independent lines of evidence suggest retinoids as causal to schizophrenia. Proc Natl Acad Sci USA 95:7240-7244.

Hawes NL, Smith RS, Chang B, Davisson M, Heckenlively JR, John SW (1999) Mouse fundus photography and angiography: a catalogue of normal and mutant phenotypes. Mol Vis 5:22-29.

Heyman I, Frampton I, van Heyningen V, Hanson I, Teague P, Taylor A, Simonoff E (1999) Psychiatric disorder and cognitive function in a family with an inherited novel mutation of the developmental control gene PAX6. Psychiatr Genet 9:85-90.

Hodgson JG, Smith DJ, McCutcheon K, Koide HB, Nishiyama K, Dinulos MB, Stevens ME, Bissada N, Nasir J, Kanazawa I, Disteche CM, Rubin EM, Hayden MR (1996) Human huntingtin derived from YAC transgenes compensates for loss of murine huntingtin by rescue of the embryonic lethal phenotype. Hum Mol Genet 5:1875-1885.

Hossain SM, Wong BKY, Simpson EM (2004) The dark phase improves genetic discrimination for some high throughput mouse behavioral phenotyping. Genes Brain Behav 3:167-177.

Iwayama-Shigeno Y, Yamada K, Toyota T, Shimizu H, Hattori E, Yoshitsugu K, Fujisawa T, Yoshida Y, Kobayashi T, Toru M, Kurumaji A, DeteraWadleigh S, Yoshikawa T (2003) Distribution of haplotypes derived from three common variants of the NR4A2 gene in Japanese patients with schizophrenia. Am J Med Genet 118B:20-24.
Jackson A, Panayiotidis P, Foroni L (1998) The human homologue of the Drosophila tailless gene (TLX): characterization and mapping to a region of common deletion in human lymphoid leukemia on chromosome 6q21. Genomics 50:34-43.

Kobayashi M, Yu RT, Yasuda K, Umesono K (2000) Cell-type-specific regulation of the retinoic acid receptor mediated by the orphan nuclear receptor TLX. Mol Cell Biol 20:8731-8739.

Krezel W, Ghyselinck N, Samad TA, Dupe V, Kastner P, Borrelli E, Chambon $P$ (1998) Impaired locomotion and dopamine signaling in retinoid receptor mutant mice. Science 279:863-867.

Kumar RA, Chan KL, Wong AH, Little KQ, Rajcan-Separovic E, Abrahams BS, Simpson EM (2004) Unexpected embryonic stem (ES) cell mutations represent a concern in gene targeting: lessons from "fierce" mice. Genesis 38:51-57.

Land PW, Monaghan AP (2003) Expression of the transcription factor, tailless, is required for formation of superficial cortical layers. Cereb Cortex 13:921-931.

Middleton FA, Pato MT, Gentile KL, Morley CP, Zhao X, Eisener AF, Brown A, Petryshen TL, Kirby AN, Medeiros H, Carvalho C, Macedo A, Dourado A, Coelho I, Valente J, Soares MJ, Ferreira CP, Lei M, Azevedo MH, Kennedy JL, et al. (2004) Genomewide linkage analysis of bipolar disorder by use of a high-density single-nucleotide-polymorphism (SNP) genotyping assay: a comparison with microsatellite marker assays and finding of significant linkage to chromosome 6q22. Am J Hum Genet 74:886-897.

Miyawaki T, Uemura A, Dezawa M, Yu RT, Ide C, Nishikawa S, Honda Y, Tanabe Y, Tanabe T (2004) Tlx, an orphan nuclear receptor, regulates cell numbers and astrocyte development in the developing retina. J Neurosci 24:8124-8134.

Monaghan AP, Grau E, Bock D, Schütz G (1995) The mouse homolog of the orphan nuclear receptor tailless is expressed in the developing forebrain. Development 121:839-853.

Monaghan AP, Bock D, Gass P, Schwager A, Wolfer DP, Lipp HP, Schutz G (1997) Defective limbic system in mice lacking the tailless gene. Nature 390:515-517.

Nguyen V, Deschet K, Henrich T, Godet E, Joly JS, Wittbrodt J, Chourrout D, Bourrat F (1999) Morphogenesis of the optic tectum in the medaka (Oryzias latipes): a morphological and molecular study, with special emphasis on cell proliferation. J Comp Neurol 413:385-404.

Ouagazzal AM, Moreau JL, Pauly-Evers M, Jenck F (2003) Impact of environmental housing conditions on the emotional responses of mice deficient for nociceptin/orphanin FQ peptide precursor gene. Behav Brain Res 144:111-117.

Owen MJ, Williams NM, O’Donovan MC (2004) The molecular genetics of schizophrenia: new findings promise new insights. Mol Psychiatry 9:14-27.

Peier AM, McIlwain KL, Kenneson A, Warren ST, Paylor R, Nelson DL (2000) (Over)correction of FMR1 deficiency with YAC transgenics: behavioral and physical features. Hum Mol Genet 9:1145-1159.

Pook MA, Al-Mahdawi S, Carroll CJ, Cossee M, Puccio H, Lawrence L, Clark P, Lowrie MB, Bradley JL, Cooper JM, Koenig M, Chamberlain S (2001) Rescue of the Friedreich's ataxia knockout mouse by human YAC transgenesis. Neurogenetics 3:185-193.

Rothermundt M, Ponath G, Arolt V (2004) S100B in schizophrenic psychosis. Int Rev Neurobiol 59:445-470.

Roy K, Kuznicki K, Wu Q, Sun Z, Bock D, Schutz G, Vranich N, Monaghan AP (2004) The Tlx gene regulates the timing of neurogenesis in the cortex. J Neurosci 24:8333-8345.

Schedl A, Ross A, Lee M, Engelkamp D, Rashbass P, van Heyningen V, Hastie ND (1996) Influence of PAX6 gene dosage on development: overexpression causes severe eye abnormalities. Cell 86:71-82.

Shi Y, Chichung Lie D, Taupin P, Nakashima K, Ray J, Yu RT, Gage FH, Evans RM (2004) Expression and function of orphan nuclear receptor TLX in adult neural stem cells. Nature 427:78-83.

Silva A, Simpson EM, Takahashi JS, Lipp H-P, Nakanishi S, Wehner JM, Giese KP, Tully T, Abel T, Chapman PF, Fox K, Grant S, Itohara S, Lathe R, Mayford M, McNamara JO, Morris RJ, Picciotto M, Roder J, Shin H-S, et al. (1997) Mutant mice and neuroscience: recommendations concerning genetic background. Neuron 19:755-759.

Stenman J, Yu RT, Evans RM, Campbell K (2003a) Tlx and Pax6 co-operate 
genetically to establish the pallio-subpallial boundary in the embryonic mouse telencephalon. Development 130:1113-1122.

Stenman JM, Wang B, Campbell K (2003b) Tlx controls proliferation and patterning of lateral telencephalic progenitor domains. J Neurosci 23:10568-10576.

Stober G, Syagailo YV, Okladnova O, Jungkunz G, Knapp M, Beckmann H, Lesch KP (1999) Functional PAX-6 gene-linked polymorphic region: potential association with paranoid schizophrenia. Biol Psychiatry 45:1585-1591.

Tandon K, McGuffin P (2002) The genetic basis for psychiatric illness in man. Eur J Neurosci 16:403-407.

Van Loo PL, Mol JA, Koolhaas JM, Van Zutphen BF, Baumans V (2001)
Modulation of aggression in male mice: influence of group size and cage size. Physiol Behav 72:675-683.

Young KA, Berry ML, Mahaffey CL, Saionz JR, Hawes NL, Chang B, Zheng QY, Smith RS, Bronson RT, Nelson RJ, Simpson EM (2002) Fierce: a new mouse deletion of Nr2e1; violent behaviour and ocular abnormalities are background-dependent. Behav Brain Res 132:145-158.

Younossi-Hartenstein A, Green P, Liaw GJ, Rudolph K, Lengyel J, Hartenstein V (1997) Control of early neurogenesis of the Drosophila brain by the head gap genes tll, otd, ems, and btd. Dev Biol 182:270-283.

Yu RT, Chiang MY, Tanabe T, Kobayashi M, Yasuda K, Evans RM, Umesono K (2000) The orphan nuclear receptor Tlx regulates Pax2 and is essential for vision. Proc Natl Acad Sci USA 97:2621-2625. 